\title{
Rates Of Suicide And Non-Fatal Suicide Attempts Among Persons Undergoing Organ Transplantation In Denmark From 1995 Through 2015
}

This article was published in the following Dove Press journal:

Clinical Epidemiology

\author{
Jaimie L Gradus (D) \\ Erzsébet Horváth-Puhó ${ }^{2}$ \\ Tammy Jiang' \\ Anthony J Rosellini $\mathbb{D}^{3}$ \\ Timothy L Lash ${ }^{4}$ \\ Henrik Toft Sørensen (iD) ${ }^{2}$ \\ 'Department of Epidemiology, Boston \\ University School of Public Health, \\ Boston, MA, USA; ${ }^{2}$ Department of \\ Clinical Epidemiology, Aarhus University \\ Hospital, Aarhus, Denmark; ${ }^{3}$ Center for \\ Anxiety and Related Disorders, Boston \\ University, Boston, MA, USA; \\ ${ }^{4}$ Department of Epidemiology, Rollins \\ School of Public Health, Emory \\ University, Atlanta, GA, USA
}

\section{Introduction}

Complications following organ transplant - such as complex medical regimens involving adherence to lifelong immunosuppressant medications, adverse effects, infection, and rejection of the transplanted organ - may increase the risk of stress and mental disorders. ${ }^{1}$ Only one population-based study has examined the association between organ transplant and suicide, and found that the suicide rate among liver transplant recipients was five times that of the Nordic general population between the years 2000 and $2010 .^{2}$ In this study, we examined associations between heart, lung, kidney, and liver transplants and suicide and non-fatal suicide attempts in the population of Denmark.

\section{Methods}

Data were from a cohort study based in the Danish national healthcare and social registries covering the entire Danish population from January 1, 1995 through December 31, 2015. Processes for linking the Danish national registries for research have been described elsewhere. ${ }^{3}$ For this study, the Danish Civil Registration System, the National Patient Registry (NPR), the Psychiatric Central Research Registry (PCRR), and the Cause-of-Death Registry were used. ${ }^{3-6}$ Transplant data were ascertained from the NPR using the Danish NOMESCO classification of surgical procedures. The transplantation cohorts consisted of persons who received an organ transplant between January 1, 1995 and December 31, 2015. For the suicide attempt analyses, transplant recipients with prior suicide attempts were excluded resulting in a sample size of 374; all persons who received an organ transplant in the time period were included in the analyses examining suicide death as an outcome $(\mathrm{n}=380)$. Persons who never received an organ transplant were matched to transplant recipients on the year of birth, sex, and calendar time, at a ratio of $10: 1$ to create a comparison cohort $(n=3740$ for the suicide attempt analyses; 3800 for the suicide death analyses). Characteristics of the sample are displayed in Table 1. Rates of non-fatal suicide attempt and suicide death were calculated among the transplant and comparison groups, as well as rate differences. Cox proportional hazards regression was used to examine associations adjusting depression, anxiety, substance abuse diagnoses, and Charlson Comorbidity Index score as a measure of physical health prior to transplantation. Confounders were
Correspondence: Jaimie L Gradus Department of Epidemiology, Boston University School of Public Health, Boston, MA, USA

Email jgradus@bu.edu 
Table I Characteristics Of The Transplantation And Comparison Cohorts, Denmark, 1995-20I5

\begin{tabular}{|c|c|c|c|c|}
\hline & \multicolumn{2}{|c|}{ Analysis Of Suicide Death } & \multicolumn{2}{|c|}{ Analysis Of Suicide Attempt } \\
\hline & $\begin{array}{l}\text { Transplant Cohort } \\
(n=380)\end{array}$ & $\begin{array}{l}\text { Comparison Cohort } \\
(n=3800)\end{array}$ & $\begin{array}{l}\text { Transplant Cohort } \\
(n=374)\end{array}$ & $\begin{array}{l}\text { Comparison Cohort } \\
(n=3740)\end{array}$ \\
\hline \multicolumn{5}{|l|}{ Sex } \\
\hline Male & 232 (61\%) & $2320(61 \%)$ & $224(60 \%)$ & $2240(60 \%)$ \\
\hline Female & I 48 (39\%) & 1480 (39\%) & $150(40 \%)$ & $1500(40 \%)$ \\
\hline Age (M, SD; years) & $46(15)$ & $46(15)$ & $46(16)$ & $46(16)$ \\
\hline Depression diagnoses & 7 ( $1.8 \%)$ & $55(1.4 \%)$ & $8(2.1 \%)$ & $66(1.8 \%)$ \\
\hline Anxiety diagnosis & $13(3.4 \%)$ & $75(2.0 \%)$ & II (2.9\%) & $73(2.0 \%)$ \\
\hline Substance abuse diagnoses & $17(4.5 \%)$ & $99(2.6 \%)$ & 17 (4.5\%) & $96(2.6 \%)$ \\
\hline $\mathrm{CCl}$ score $\leq \mathrm{I}$ & 339 (89\%) & 430 (1 I\%) & 334 (89\%) & $43 \mathrm{I}(12 \%)$ \\
\hline Follow-up time (M, SD) & $9.2(8.1)$ & $12(8.5)$ & $9.3(8.1)$ & $12(8.6)$ \\
\hline
\end{tabular}

Notes: Sizes of the examined cohorts differ by outcome due to the exclusion of persons with prior suicide attempts from the suicide attempt analyses. Cells with a sample size under 5 are not shown.

selected based on the prior literature. This study was determined to be exempt from review by the Boston University IRB approved by the Danish Data Protection Agency (record number 2015-57-0002). SAS version 9.4 was used for all analyses.

\section{Results}

In total, 20 persons who had transplants died by suicide during the study period and 16 made a non-fatal suicide attempt (the comparable numbers among the comparison cohort were 131 and 161, respectively). Persons in the transplant cohort were more likely than persons in the comparison cohort to have previous psychiatric diagnoses and a Charlson Comorbidity Index score of 1 or greater prior to transplant date/index date (Table 1). Among those who received an organ transplant, the suicide rate was 5.6/1000 person-years and the nonfatal suicide attempt rate was $4.6 / 1000$ person-years (Table 2). The rates among those who did not receive transplants were 2.8/1000 person-years and 3.6/1000 person-years, respectively. In comparing those who did and did not receive transplants (Table 2), the rate difference for suicide was 2.9/1000 person-years $(95 \%$ confidence interval [CI]: $0.3,5.4$ per 1000 personyears) with an adjusted hazard ratio of 1.8 (95\% CI: $0.9,3.6)$. The rate difference for incident non-fatal suicide attempt was 1.0/1000 person-years (95\% CI: -1.3 , 3.3 per 1000 person-years) with an adjusted hazard ratio of $1.1(95 \% \mathrm{CI}: 0.50,2.3)$.

\section{Discussion}

This study found some evidence of an increased rate of death from suicide, but not non-fatal suicide attempt, among patients who received an organ transplant. The explanation for the elevated rate of death from suicide among persons who receive organ transplants, without similar elevation of non-fatal suicide attempt, is likely complex and a challenge to elucidate from our observations. Suicidal intent may be high among persons who receive a transplant, and thus a large proportion

Table 2 Rates And Associations Between Organ Transplants And Non-Fatal Suicide Attempt And Suicide Death, Denmark, 1995-2015

\begin{tabular}{|l|l|l|}
\hline & Suicide Death & Suicide Attempts \\
\hline Received transplant & $5.6 / 1000 \mathrm{PY}$ & $4.6 / 1000 \mathrm{PY}$ \\
No transplant & $2.8 / 1000 \mathrm{PY}$ & $3.6 / 1000 \mathrm{PY}$ \\
Rate difference $(95 \% \mathrm{Cl})$ & $2.9 / 1000 \mathrm{PY}(0.3 / 1000 \mathrm{PY}, 5.4 / 1000 \mathrm{PY})$ & $1.0 / 1000 \mathrm{PY}(-1.3 / 1000 \mathrm{PY}, 3.3 / 1000 \mathrm{PY})$ \\
Adjusted hazard ratio $(95 \% \mathrm{Cl})^{\mathrm{b}}$ & $1.8(0.9,3.6)$ & $1.1(0.50,2.3)$ \\
\hline
\end{tabular}

Notes: ${ }^{\text {aPY}}=$ person-years; ${ }^{\mathrm{b}}$ Adjusted for sex, year of birth, depression, anxiety, substance abuse diagnoses and Charlson Comorbidity Index score prior to transplantation. 
of suicide attempts in this population may result in fatality. Persons who receive a transplant may also have access to highly lethal means of death related to their compromised health status. Further, inflammatory or metabolic changes that occur during an organ transplant may increase the risk for certain psychiatric disorders (e.g., depression) and suicide. ${ }^{7,8}$ The rates of death from suicide and non-fatal suicide attempt were comparable among persons who received transplants; differences in the relative effects arise more from differences in the death from suicide and suicide attempt rates among persons in the comparison groups. These may be true differences, differences in classification accuracy across groups (e.g., misclassification of suicide attempt), or both. Further, our confidence intervals indicate that our associations are imprecisely measured, likely owing to sample size. Despite these limitations, clinicians treating transplant patients should be aware of the possibility of an increased rate of suicide following organ transplant.

\section{Acknowledgments}

This work was supported by NIMH grant \# 5R01MH109507

(PI: Gradus) and by a grant \# R248-2017-521 from the Lundbeck Foundation (PI: Sørensen).

\section{Disclosure}

Dr Timothy L Lash reports grants from US NIH, during the conduct of the study. The authors report no other conflicts of interest in this work.

\section{References}

1. Dew MA, Rosenberger EM, Myaskovsky L, et al. Depression and anxiety as risk factors for morbidity and mortality after organ transplantation: a systematic review and meta-analysis. Transplantation. 2015;100(5):988-1003. doi:10.1097/TP.000000000 0000901

2. Åberg F, Gissler M, Karlsen TH, et al. Differences in long-term survival among liver transplant recipients and the general population: a population-based Nordic study. Hepatol Baltim Md. 2015;61(2):668677. doi: $10.1002 /$ hep. 27538

3. Schmidt M, Schmidt SAJ, Sandegaard JL, Ehrenstein V, Pedersen L, Sørensen HT. The Danish national patient registry: a review of content, data quality, and research potential. Clin Epidemiol. 2015;7:449490. doi:10.2147/CLEP.S91125

4. Pedersen CB. The Danish civil registration system. Scand J Public Health. 2011;39(7 Suppl):22-25. doi:10.1177/1403494810387965

5. Mors O, Perto GP, Mortensen PB. The Danish psychiatric central research register. Scand J Public Health. 2011;39(7 Suppl):54-57. doi: $10.1177 / 1403494810395825$

6. Helweg-Larsen K. The Danish register of causes of death. Scand J Public Health. 2011;39(7 Suppl):26-29. doi:10.1177/1403494811399958

7. Molassiotis A, Morris PJ. Suicide and suicidal ideation after marrow transplantation. Bone Marrow Transplant. 1997;19(1):87-90. doi:10.1038/sj.bmt.1700605

8. Hoffmeister P, Storer B, Syrjala K, Baker K. Physician-diagnosed depression and suicides in pediatric hematopoietic cell transplant survivors with up to 40 years of follow-up. Bone Marrow Transplant. 2016;51(1):153-156. doi:10.1038/bmt.2015.233
Clinical Epidemiology

\section{Publish your work in this journal}

Clinical Epidemiology is an international, peer-reviewed, open access, online journal focusing on disease and drug epidemiology, identification of risk factors and screening procedures to develop optimal preventative initiatives and programs. Specific topics include: diagnosis, prognosis, treatment, screening, prevention, risk factor modification, systematic reviews, risk \& safety of medical interventions, epidemiology \& biostatistical methods, and evaluation of guidelines, translational medicine, health policies \& economic evaluations. The manuscript management system is completely online and includes a very quick and fair peer-review system, which is all easy to use. 